\title{
Structural design and analysis on a large span dry-coal-shed with three cylindrical reticulated shell
}

\author{
XUAN WANG ${ }^{1, a}$ \\ ${ }^{1}$ EAST CHINA ELECTRIC POWER DESIGN INSTITUTE CO.,LTD,SHANG HAI,CHINA \\ wangxuan3005@ecepdi.com
}

\begin{abstract}
Keywords: dry-coal-shed; three cylindrical reticulated shell; analysis and design; structure design software

Abstract. The large span dry-coal-shed has complicated structure,which has the large-span of $114 \mathrm{~m}$ and the vertical section of $20 \mathrm{~m}$. In this paper, the whole project has been expounded in different ways, such as stress analysis,structure selection, structure design. Two different structure design softwares(MST and 3D3S) have been used to compare the analysis results, structure characteristic and component selection.On this basis, a design flow based on Two different structure design softwares has been created.The result show that: a large span dry-coal-shed with three cylindrical reticulated shell can reduce the amount of steel and optimize design method by using the design flow.
\end{abstract}

\section{Introduction}

This project is a large span dry-coal-shed with openings at both ends, it is composed by the main structure, roof enclosing structure, horse Road lighting and other auxiliary components. The main structure of double-layer steel structure reticulated shell, the horizontal span of 114 meters, the longitudinal length of 160 meters, headroom requirements of not less than $23.5 \mathrm{~m}$.Roof retaining structure is mainly composed of purlin and single laminated steel plate; the auxiliary part is composed of lighting system, overhauling horse road and fire protection system ${ }^{[1-4]}$.

\section{Structural design}

Double-layer cylindrical reticular shell has many forms, it is mainly composed by the cross-truss system and the pyramid system. Cross-truss system: Single-layer cylindrical reticulated shell form can be double-cross cylindrical truss system. Tetragonal cone composed of double-layer cylindrical reticulated shell: positive quadrangular pyramid cylindrical reticular shell, taking the time to put the quadrangular pyramid cylindrical reticulated shell and the positive quadrangular pyramid is placed in the reticulated shell. The research shows that in many structural systems, the truss-type reticulated shell has poor space force performance and poor lateral stability. Inclined square pyramid is placed in the reticular shell force transmission is not direct, easily formed at both ends of the hole stress concentration. Positive quadrangular pyramidal reticular shell force transmission path through the chord to the force passed directly to the vicinity of the support, while the form by the quadrangular pyramid is a combination of certain rules, the rod less category, node structure Simple, high stiffness, so the project uses the whole form of quadrangular pyramid.

The geometric dimensions of dry coal shed section are mainly determined by the operation requirements of coal stacking and coal yard machinery. At the same time, its force performance and shape parameters are closely related. Span to the grid size, the number of grids (span direction), floor angle and reticulate shell thickness changes will cause dry coal shed technical and economic indicators of change. When the other indexes remain unchanged, with the increase of grid size, the height of grid shell increases, the peak of internal force decreases, the deflection of structure decreases, the horizontal thrust decreases, but the amount of steel increases. After optimization of the geometrical dimensions, the grid span of $3950 \mathrm{~mm}$ and the grid of 44 grids were determined. The radius of the large circle was $R=134.714 \mathrm{~m}$, the angle of the arc was 42.3932 degrees, the number of grids was 26, and the radius of the small circle was $9.451 \mathrm{~m}$, angle between the arc 81.5672 degrees, 
the number of grids 4; floor angle 1.9004 degrees; reticulation shell thickness of 3 meters. The overall structure of the reticular shell vector high 37.520 meters, expand the area of $27256 \mathrm{~m}^{2}$, projection area of $18240 \mathrm{~m}^{2}$.

The main design load of reticulated shell are: (1) Dead load: $0.3 \mathrm{KN} / \mathrm{m}^{2}$ (upper layer), $0.1 \mathrm{KN} / \mathrm{m}^{2}$ (lower layer); (2) Live load: $0.5 \mathrm{kN} / \mathrm{m}^{2}$; / m2; (4) Temperature effect: The project takes +20 degrees (positive temperature difference) and -20 degrees (negative temperature difference); (4) Earthquake effect: Seismic fortification intensity is 7 degrees; A case of basic wind pressure $0.4 \mathrm{kN} / \mathrm{m}^{2}$, surface roughness category B class. Therefore, the wind load is the main load of the structure. Generally, the body coefficient of the trilocular reticulated shell is determined by wind tunnel test. The project organizes the body type coefficients of the same type according to the correlation Specification to determine the body factor as shown in Table 1:

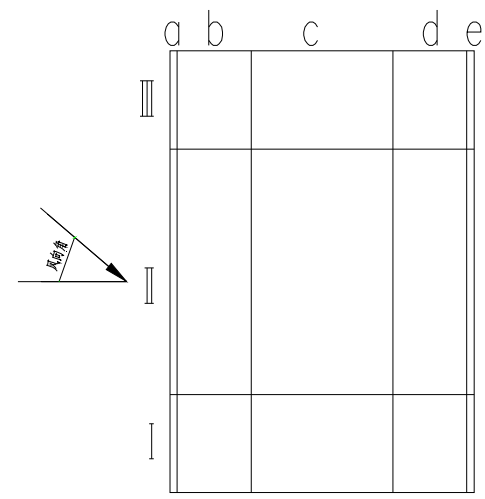

Table1 Wind load body coefficient

\begin{tabular}{|c|c|c|c|c|c|c|c|c|c|c|c|}
\hline \multirow{2}{*}{ Angle } & \multirow{2}{*}{$\begin{array}{c}\text { Partitio } \\
n\end{array}$} & \multicolumn{5}{|c|}{ outer surface } & \multicolumn{5}{|c|}{ inner surface } \\
\hline & & $a$ & $b$ & $c$ & $d$ & e & $a$ & b & $c$ & $d$ & e \\
\hline $0^{\circ}$ & I II III & 1.0 & .0 .5 & $\cdot 1.7$ & .0 .7 & .0 .6 & .0 .6 & .0 .6 & -0.7 & .0 .5 & .0 .5 \\
\hline \multirow{3}{*}{$\neq 0^{\circ}$} & I & 0.8 & $\cdot 0.2$ & .1 .6 & .1 .4 & $\cdot 1.2$ & -0.7 & .0 .7 & .0 .5 & 0.9 & 1.2 \\
\hline & II & 0.6 & -0.4 & $\cdot 1.5$ & -1.0 & -0.7 & -0.5 & -0.5 & -0.5 & -0.2 & .0 .2 \\
\hline & III & 0.9 & -0.2 & $\cdot 1.4$ & $\cdot 0.5$ & -0.6 & -0.4 & -0.6 & -0.5 & .0 .4 & .0 .5 \\
\hline
\end{tabular}

\section{The two software structure calculation and analysis}

The project uses MST2011 structural analysis software to analyze and design and verify through 3D3S software. MSTCAD uses a full stress design for structural optimization. The full stress method assumes that the stress of each rod reaches the maximum stress, and the rod is utilized to the fullest extent so that the total mass of the structure is minimized. Full stress design method [8]: First estimate the initial cross-sectional area of the design variables $\mathrm{AR}^{\mathrm{K}}=\left(\mathrm{AR}_{1}{ }^{\mathrm{K}}, \mathrm{AR}_{2}{ }^{\mathrm{K}}, \ldots \ldots \mathrm{AR}_{\mathrm{n}}{ }^{\mathrm{K}}\right)$, through the mechanics analysis of each condition to get the maximum stress of the rod under each condition $\sigma_{\max }{ }^{K}=\max \left(\sigma_{i j}{ }^{K}\right)$, Where $i$ is the number of each bar, $j$ is the case number. The maximum stress of each rod $\sigma_{\max }{ }^{K}$ and allowable stress $\mathrm{M}_{\mathrm{i}}^{\mathrm{K}}=\sigma_{\max } \mathrm{K}_{/[}$allowable stress], multiple iterations $\mathrm{AR}^{\mathrm{K}+1}=\mathrm{M}_{\mathrm{i}}^{\mathrm{K}} \cdot \mathrm{AR}^{\mathrm{K}}$, until the overall structural mass $=\sum \mathrm{AR}^{\mathrm{K}+1} \cdot 1$ minimum.

The current project usually requires the calculation of the same structural model of the calculation software review, the project uses 3D3S for checking. MST2011 interface file export function is limited, the entity structure model (rod information, load, boundary conditions, combination of conditions, etc.) can not be fully converted, so the "section approximation" method for checking. The principle of the method is as follows: the 3D line model (that is, only the CAD model of point and line) is output through the MST, and the 3D3S is imported and the definition of the combination of the load information, the load, the boundary condition and the working condition is repeated. Which need to control 3D3S software cross-section library and MST consistent (that is, the software can only be selected in which rod), because the geometry of the two models are consistent, its internal force distribution is very close to the same through the same stress ratio control, the same position The cross-section of the components is basically the same. However, the full stress design of 3D3S is slightly different. In the MST full stress design method, the maximum stress of each rod, 6maxK, is 
obtained during the first internal force calculation. Subsequent cross-sectional adjustment no longer considers the influence of cross-section changes on the original internal force distribution. But 3D3S full stress design method, with each cross-section adjustment, need to re-calculate the internal force, which makes the stress ratio of the rod each time corresponds to the "latest" internal force. Two software calculation process shown in Figure 2.

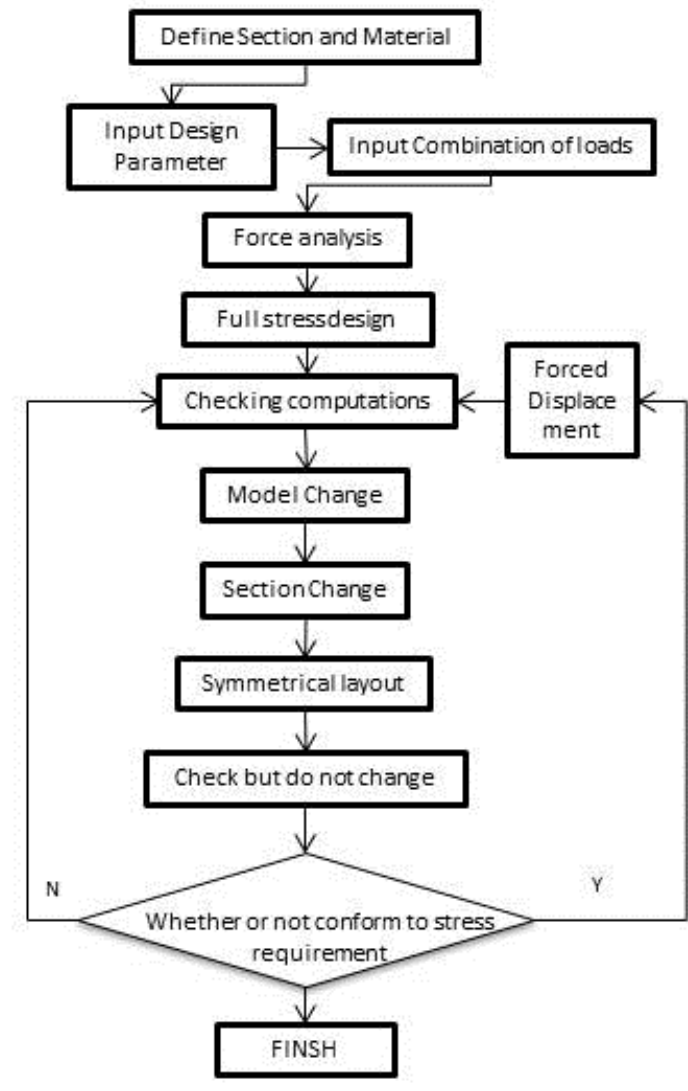

MST full stress flow

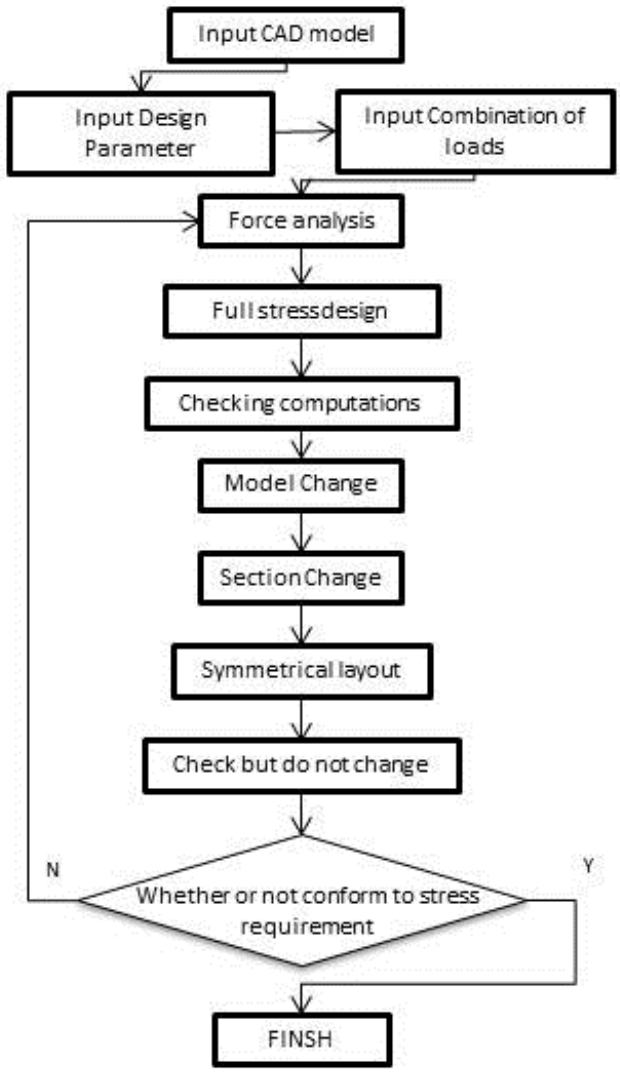

3D3S full stress flow

Figure 2. Calculation of two software design flow

As can be seen from Figure 2, the two software in the full design of the idea of stress is the same, only in the internal force analysis are different, the two analysis methods have their own strengths and weaknesses, through the estimated section of the initial internal forces and structures to determine the final Of the actual stress is slightly different, but for the reticulated shell structure is completely acceptable, when the internal forces are always constant value for the follow-up section adjustment has brought great benefits, with fewer adjustments can be completed all the sections Full stress design. When the internal force changes with the change of cross section, each newest internal force will not satisfy the new stress ratio for the current cross section, thus requiring repeated cross section adjustment.

\section{Structural analysis of the results contrast}

Finished structural analysis of post-processing results need to be compared, the designer is most concerned about the selection of structural members, the stress ratio of the rod and other parameters. In the process of comparison, special attention should be paid to the selection of the cross-section of the rod in the key part. Taking the double-layer reticulated shell structure as an example, the maximum stress occurs at the support. For this project, the maximum stress occurs in the small radius area, Vertical segment can be considered the same role with the general column, two software final model shown in Figure 3. Because of the large number of model parts, it is difficult to expand the stress ratio of all the members in this paper. The four macro-indicators of structure cycle, bearing reaction force, model bar and structure steel are selected for comparison. Take the first six cycles of the model for comparison, as shown in Table 2. 
Table2 Period comparison

\begin{tabular}{|l|l|l|l|l|l|l|}
\hline MST & $\mathrm{T} 1=2.1864$ & $\mathrm{~T} 2=1.1549$ & $\mathrm{~T} 3=0.9984$ & $\mathrm{~T} 4=0.9896$ & $\mathrm{~T} 5=0.8921$ & $\mathrm{~T} 6=0.8361$ \\
\hline 3D3S & $\mathrm{T} 1=2.0375$ & $\mathrm{~T} 2=1.0390$ & $\mathrm{~T} 3=0.9865$ & $\mathrm{~T} 4=0.9554$ & $\mathrm{~T} 5=0.8640$ & $\mathrm{~T} 6=0.8179$ \\
\hline
\end{tabular}

Take the bearing support force of 8 supports in the model for comparison, where $\mathrm{X}$ is the length direction, $\mathrm{Y}$ is the span direction, and $\mathrm{Z}$ is the vertical direction $(\mathrm{KN})$.

\begin{tabular}{|l|l|l|l|l|l|l|l|}
\hline $\begin{array}{l}\text { Support1 } \\
\text { (MST) }\end{array}$ & $\begin{array}{c}\text { Support2 } \\
\text { (MST) }\end{array}$ & $\begin{array}{c}\text { Support3 } \\
\text { (MST) }\end{array}$ & $\begin{array}{c}\text { Support4 } \\
\text { (MST) }\end{array}$ & $\begin{array}{c}\text { Support5 } \\
\text { (MST) }\end{array}$ & $\begin{array}{c}\text { Support6 } \\
\text { (MST) }\end{array}$ & $\begin{array}{c}\text { Support7 } \\
\text { (MST) }\end{array}$ \\
\hline $\mathrm{Rx}=-447 / 316$ & $\mathrm{Rx}=-279 / 242$ & $\mathrm{Rx}=-246 / 212$ & $\mathrm{Rx}=-219 / 185$ & $\mathrm{Rx}=-142 / 128$ & $\mathrm{Rx}=-115 / 108$ & $\mathrm{Rx}=-105 / 102$ & $\mathrm{Rx}=-95 / 93$ \\
\hline $\mathrm{Ry}=-381 / 249$ & $\mathrm{Ry}=-519 / 359$ & $\mathrm{Ry}=-482 / 345$ & $\mathrm{Ry}=-492 / 353$ & $\mathrm{Ry}=-480 / 349$ & $\mathrm{Ry}=-470 / 349$ & $\mathrm{Ry}=-462 / 347$ & $\mathrm{Ry}=-462 / 350$ \\
\hline $\mathrm{Rz}=-336 / 1134$ & $\mathrm{Rz}=-228 / 939$ & $\mathrm{Rz}=-159 / 974$ & $\mathrm{Rz}=-247 / 1011$ & $\mathrm{Rz}=-257 / 999$ & $\mathrm{Rz}=-180 / 995$ & $\mathrm{Rz}=-205 / 991$ & $\mathrm{Rz}=-213 / 1011$ \\
\hline $\mathrm{S} 1(3 \mathrm{D} 3 \mathrm{~S})$ & $\mathrm{S} 2(3 \mathrm{D} 3 \mathrm{~S})$ & $\mathrm{S} 3(3 \mathrm{D} 3 \mathrm{~S})$ & $\mathrm{S} 4(3 \mathrm{D} 3 \mathrm{~S})$ & $\mathrm{S} 5(3 \mathrm{D} 3 \mathrm{~S})$ & $\mathrm{S} 6(3 \mathrm{D} 3 \mathrm{~S})$ & $\mathrm{S} 7(3 \mathrm{D} 3 \mathrm{~S})$ & $\mathrm{S} 8(3 \mathrm{D} 3 \mathrm{~S})$ \\
\hline $\mathrm{Rx}=-495 / 347$ & $\mathrm{Rx}=-235 / 220$ & $\mathrm{Rx}=-246 / 200$ & $\mathrm{Rx}=-208 / 170$ & $\mathrm{Rx}=-116 / 109$ & $\mathrm{Rx}=-107 / 103$ & $\mathrm{Rx}=-97 / 92$ & $\mathrm{Rx}=-87 / 82$ \\
\hline $\mathrm{Ry}=-393 / 220$ & $\mathrm{Ry}=-535 / 327$ & $\mathrm{Ry}=-513 / 347$ & $\mathrm{Ry}=-498 / 337$ & $\mathrm{Ry}=-499 / 330$ & $\mathrm{Ry}=-491 / 324$ & $\mathrm{Ry}=-489 / 324$ & $\mathrm{Ry}=-486 / 322$ \\
\hline $\mathrm{Rz}=-387 / 1119$ & $\mathrm{Rz}=-182 / 1001$ & $\mathrm{Rz}=-163 / 1015$ & $\mathrm{Rz}=-280 / 999$ & $\mathrm{Rz}=-252 / 1021$ & $\mathrm{Rz}=-205 / 990$ & $\mathrm{Rz}=-184 / 989$ & $\mathrm{Rz}=-271 / 1022$ \\
\hline
\end{tabular}

The above-mentioned structure cycle, bearing reaction force, the model with rod diagram, the amount of structural steel compared the four macro indicators can be drawn from the results of the comparison, the two models are very close to the indicators, indicating that the control section library Combination with the conditions, the two software with the same stress than the rod with the results closer to the comparison between the two can be well achieved. Designers can compare the two models with the rod diagram, the corresponding section of the key area to adjust, with the section of the section of the library type of subdivision, the two software with the rod section will tend to be consistent.

\section{Conclusion}

(1) In this paper, the idea of structure design of dry coal shed is put forward from the aspects of structure form, geometrical parameters, boundary design conditions and design loads, and the structural arrangement with good structural performance and economy can be obtained by controlling the control conditions and parameters.

(2) Aiming at the limitation of current MST software conversion function, the method of "section approximation" in 3D3S software is put forward for checking. By studying the mechanism of stress analysis of the two softwares, Feasible checking method.

(3) The comparison of the four macroscopic indexes of structure cycle, bearing reaction force, model bar diagram and structure steel shows that the method described in this article can solve the problem of current model re-estimation very well, Designers adjust to key areas of structure.

\section{References}

[1] YE Mengyang, Gu Ming: Wind tunnel experinent study on shape coefficient of large span dry coal sheds:Structural Engineers.Vol 23 (2007), p. 65

[2] LIU SHIYU, FAN ZHEN: The sinulating testing of wind loading in wind runnel in dry coal shed latticed shell:Structural Engineers.Vol 04 (2006), p. 67

[3] HuangPeng, GuMing: Experimental study on wind loads on cylindriacl reticulated shells: Building Structure.Vol 04 (2011), p.1432

[4] GUOYun,ChenHui:Structural design and anlysis on the large-span dry coal shed in thermo power station. Vol 45 (2015), p.49 